\title{
The local library across the digital and physical city: Opportunities for economic development
}

Commonwealth Journal of Local Governance

Issue 15: June 2014

http://epress.lib.uts.edu.au/ojs/index.php/cjlg

\section{Kirralie Houghton}

Institution for Creative Industries \& Innovation Queensland University of Technology

Australia

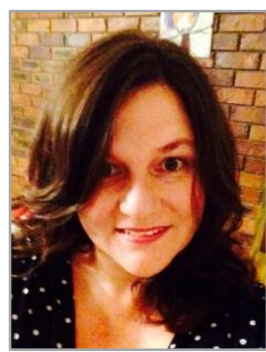

\section{Abstract}

This paper considers the role of the public library as a community hub, engagement space, and entrepreneurial incubator in the context of the city, city governance, and local government planning. It considers this role from the perspective of library experts and their future visions for libraries in a networked knowledge economy. Public libraries (often operated by or on behalf of local governments) potentially play a pivotal role for local governments in positioning communities within the global digital network. Fourteen qualitative interviews with library experts informed the study which investigates how the relationship between digital technology and the physical library space can potentially support the community to develop innovative, collaborative environments for transitioning to a digital future. The study found that libraries can capitalise on their position as community hubs for two purposes: first, to build vibrant community networks and forge economic links across urban localities; and second, to cross the digital divide and act as places of innovation and lifelong learning. Libraries provide a specific combination of community and technology spaces and have significant tangible connection points in the digital age. The paper further discusses the potential benefits for libraries in using ICT networks and infrastructure, such as the National Broadband Network in Australia. These networks could facilitate greater use of library assets and community knowledge, which, in turn, could assist knowledge economies and regional prosperity.

Keywords: Libraries, national broadband, community, community hub, library governance, urban informatics

\section{Introduction}

Internet and digital technologies are impacting on many aspects of modern society, from economics and politics, culture and art, science and research (OEDC 2012). Much more than just a communication tool, OECD research suggests that digital technology 'has transformed into ubiquitous technology supporting all sectors across the economy' and become a fundamental infrastructure of our time (OEDC 2012). In response to this phenomenon, the Australian Government has developed The National Digital Economy Strategy (DBCDE 2011a) and in 2011 committed to establishing a National Broadband Network (NBN) at an estimated cost of AU\$48 billion over three years. This broadband rollout will increase the connectivity of Australians, with an estimated net economic benefit of AU\$9.5 billion to Australia’s GDP (Access Economics 2009). 
In the implementation strategy of the NBN, a number of public libraries across the country have been chosen as central technology hubs for communities, as an extension of their current roles as educators, knowledge suppliers, and community places. Research has already established that public libraries play a sometimes quiet, but significant, role in the local economy. For example, in a meta-analysis of 38 studies into the economic value of libraries, Aabø (2009) estimated that for every dollar spent on libraries, they return four to five times the value to their community. Similarly, the State Library of Queensland calculates a return of AU $\$ 2.30$ to AU\$4.10 for every dollar spent on libraries across that state (SLQ 2012). Contributing AU\$295 million to the Gross State Product of Queensland, the total annual income generated was estimated to be AU\$614 million (SLQ 2012).

This paper explores how some public libraries are interpreting and capitalising on their changing role and envisaging ways to maximise the potential advantages of digital technology, and maintain relevance in an increasingly digital knowledge economy. Central to this study is the relationship between technology and the physical library space, and how this relationship could support the needs of the community and develop innovative, collaborative environments for transitioning to a digital future. The study's findings may stimulate all levels of government, and in particular local government (which in Australia carry the main responsibility for public library services) to investigate ways of leveraging libraries for capitalising on the benefits and uses of digital technologies in order to position their communities for competitive advantage. Research findings about this critical relationship were derived from an analysis of data collected using qualitative expert interviews with policy advisors, department heads, library managers, state government consultants to libraries, and information technology (IT) librarians.

This study focuses on the opportunity to place the library as a community hub, an engagement space, and an entrepreneurial incubator within the greater context of the city, city governance, and local government planning. Such opportunities for local government may include the use the existing infrastructure of libraries to increase their impact on local economies to extend digital services and connections within their communities. This paper starts by presenting the supporting literature and context of libraries in the digital economy, including their role as a physical place and community hub, and the types of learning and connections they support. It then outlines the methodology and findings of the expert interviews with library managers and policy consultants, draws out the key implications from their perceptions and experiences in the discussion, and concludes with recommendations and directions for the positioning of libraries within city governance in the future. 


\section{Literature review}

\section{The evolving needs of the digital age and digital economy}

In 2009, Australia's federal government announced the National Broadband Network (NBN) initiative that would direct the future development of telecommunications across Australia (DBCDE 2009). The aim of the initiative was to increase the nation's productivity and competitiveness, and - via more indirect flow-on effects - to improve the general social wellbeing of its citizens and residents. The digital economy, dynamic in nature, presents opportunities for Australia to engage and grow new markets and shrink the vast distances across the continent. It is noted within the Digital Economy Future Directions Final Report that infrastructure alone is not enough to generate this economy - it needs to be supported by the use and contributions of individuals across the nation (Cradduck 2011), a view further supported by OECD (2012) research. Many of the opportunities and much of the responsibility for training the nation in preparation for the new digital future will rest with local governments. The tasks of training the nation's workforce in the relevant skills and ensuring access to technology present their own set of challenges. This study further illustrates the crucial role that local libraries can play in meeting these new challenges and obligations.

To connect more Australians, a Digital Communities initiative established a number of 'Digital Hubs' in locations around Australia (shown in Table 1). These are based in areas that were targeted for the first NBN rollout begun in 2011 (DBCDE 2011b). The majority of the hubs (27 of the total 30) are run under the auspices of local government owned public libraries, which emphasises a role that libraries across Australia have already assumed as digital educators, facilitating a link or bridge across the digital divide (Hull 2003; McShane 2011; Notley and Foth 2008). The management and ongoing nurture of the digital hubs beyond the initial NBN deployment phase will reside within local government responsibilities and be closely tied to their management of local libraries. In a survey of Internet use in libraries conducted by the Australian Library and Information Association (AGIMO), $37 \%$ of libraries surveyed felt that the NBN would increase the usage of their libraries (ALIA 2012). Comments from their survey also suggested that some libraries saw that the improvements to Internet speeds through the NBN rollout would positively support the services they offered. Another name used for digital hubs has been 'community technology centres' (CTC) (Hayden \& Ball-Rokeach 2007).

In 2004, Strover, Chapman, and Waters presented research into 36 CTCs across Texas, USA. They used both qualitative and quantitative methods to evaluate the way these CTCs were established and managed. Their paper outlined the challenges of enlisting the support of multiple government departments, along with the two main assumed benefits of providing access and training in Internet technology: economic development and civic engagement. 
Table1: Designated NBN digital hubs across Australia by state, adapted from the NBN Website

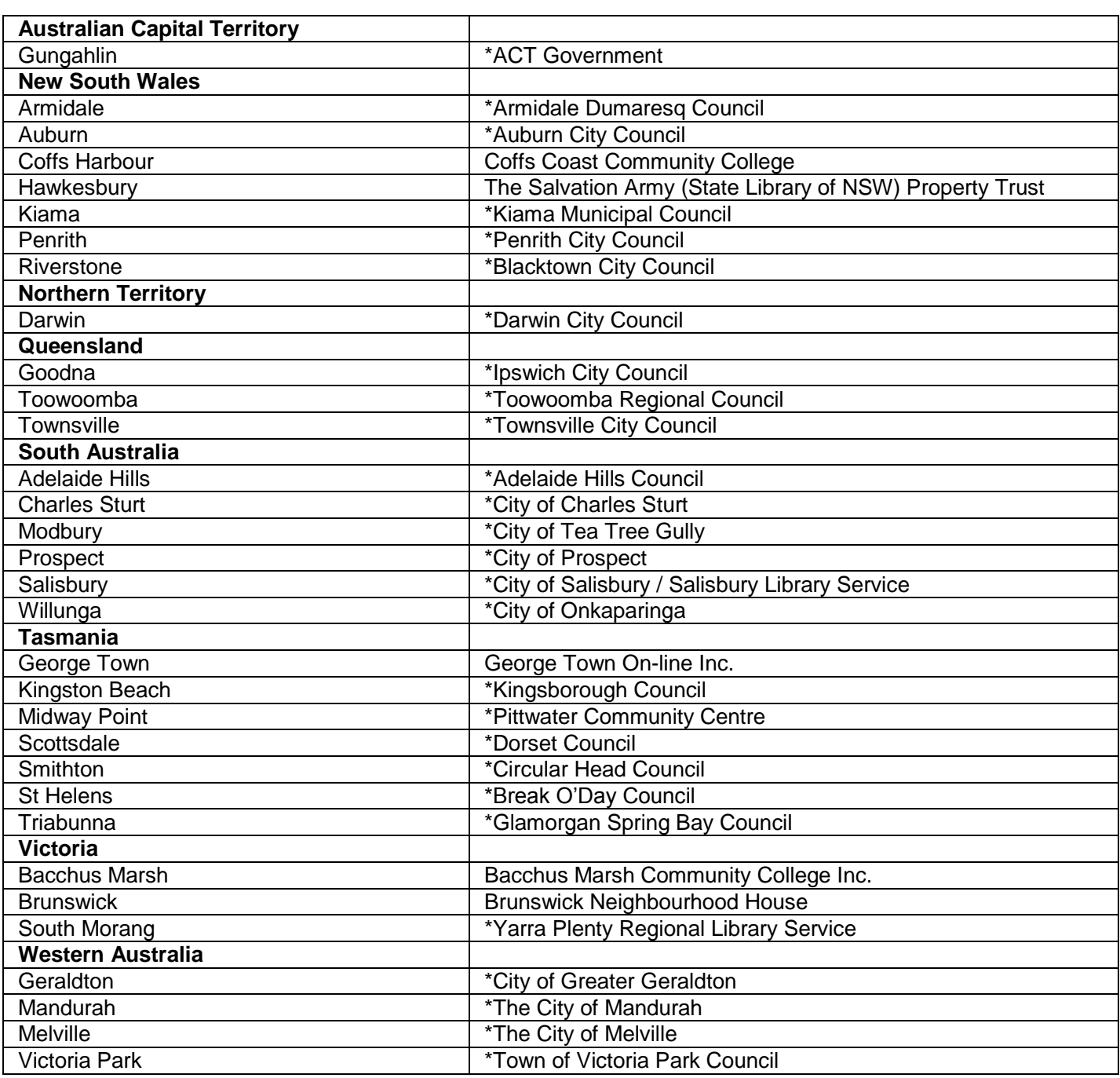

* Digital hub located in a library

Source: Government Website NBN - National Broadband Network - Australia (DBCDE, 2011b)

In line with Gurstein (2003) their research confirmed that the infrastructure alone was not enough to advance the effective use of accessing the technical infrastructure alone, or to create the economic benefits sought. The paper stressed that in many fundamental ways, building community is a necessary precursor to building a successful community network' (Strover, Chapman and Waters 2004, p. 432). The paper criticised the choice of libraries and schools as places to establish CTCs. This criticism was based on two main factors: First, these institutions provided limited times of access (in the case of schools); and second, they reinforced existing power structures within communities and were, therefore, not truly public realms open to all. Newman (2007) refuted this criticism, arguing that the public library can be considered one of the last truly public realms, and this has been an intrinsic value of libraries since the 19th century (Cubitt 2006; Quinn and McCallum 2011). 
Public libraries provide access to information across diverse demographics and cultures (Russell and Jie Huang 2009). Newman (2007), in her account of British public libraries as public realms, states that the library 'promoted an image of free and open society' in its provision of 'access to common public culture' and 'opportunities for self education' (p. 892). Strover et al. (2004) established that locations that had other social or entertainment value to attract people were the most successful CTCs, because people work best in a dynamic social environment with activity and life.

The establishment of digital hubs within public libraries acknowledges specific key characteristics of libraries that will become of increasing significance to local governments moving forward: they represent the public realm (Newman 2007); they are perceived as 'third places' or social places of community connection (Aabø and Audunson 2012; Buschman and Leckie 2007; Oldenburg 1989); they are a building block of local community (Chowdhury, Poulter and McMenemy 2006); they are perceived as places of lifelong learning (Bilandzic 2013; Jehlik 2004) and leisure (Hayes and Morris 2005); and they are, for many, a point of connection with knowledge through a wide variety of media (Jehlik 2004). The melding of social and work environments in the digital age could see the reinvention of working spaces. The freedom to move away from the office but retain connectivity opens up opportunities for libraries to provide an alternative office space. This is particularly relevant to small offices and owner operated enterprises, although not limited to these small organisations.

Proposing a new model for public libraries in a digital age, Chowdhury et al. (2006) argue that the library is in an influential position to support the ambitions of local government for the creation, collection, and preservation of community knowledge. Within their work community knowledge was seen as a dynamic and evolving process that takes libraries to a new 'Web 2.0 model.' This term is used in reference to the second generation of the World Wide Web, which is characterised by its social interaction, its dynamic nature, its ability to create online communities, and the fact that it is free (Hardey 2007; Hull 2003; Kolbitsch 2006). Using this model, library services are re-evaluated in light of user needs and the opportunities of new technologies (Chowdhury, Poulter and McMenemy 2006). The balance of basic computer literacy and robust infrastructure is significant if the community is to fully realise this potential - not only for social and recreational purposes, but also for economic development and regional sustainability objectives.

As knowledge becomes a key resource in this digital age (in which old economies shift to knowledgebased economies), it is pertinent to understand how knowledge is acquired, generated, and expanded (Leadbeater 2000). This can then be applied to position local communities and local government areas. The focus is on using the specific strengths of a community to further establish the necessary markets and connections to gain critical advantages. 


\section{Social connection and social learning: the role of libraries}

Social connections play a major role in the process of learning, and more particularly, in the process of innovating. Tuomi (2002) argues that our social connections and behaviours are the generators of communities of practice (Wenger, McDermott and Snyder 2002). Once a technology has been adopted and used across society, it begins to take a meaningful role within our culturally constituted world. Culture is socially constructed; it provides a way in which we view or understand the world, including our understanding of technology such as the Internet (Tuomi 2002). There are divergent views on the definition of culture and pinning down its exact meaning is problematic (Jahoda 2012). For this study, we draw on the classic work of Kroeber and Kluckhohn (1952) and consider it as a social heritage or tradition. Their own definition suggests it is the patterns of behaviour, acquired and transmitted, 'constituting the distinctive achievement of human groups,' and suggesting 'culture systems may, on one hand, be considered as products of action and on the other as conditioning elements of further action' (p. 181). Digital technologies are both artefacts of our culture and actions and have a bearing on our modern culture.

Bringing people together in a place (for instance, the library or a technology hub) is an effective way to generate knowledge through social engagement and practice. Creating a practice of innovation involves creating communities that share a practice or use of technology. Increasing the use of technology, or the reproduction of the social practice of technology, allows for the innovation, personalisation, or a new appropriation of a practice. This reinvention or adaptation is part of a process of creating innovation, which is encouraged when people divert resources for unintended purposes (Tuomi 2002). Wenger (2002) outlined seven actions that could cultivate communities of practice. Shown in Table 2, these actions can be applied to a range of settings, although they particularly resonate with libraries.

Table 2: Seven actions for cultivating communities of practice Source: Adapted from Wenger

\begin{tabular}{|c|c|}
\hline Step & Description \\
\hline 1 & $\begin{array}{l}\text { Design the community to evolve naturally. A Community of Practice (CoP) is dynamic and subject to } \\
\text { change in interests, goals, and members. The design of a CoP should allow for shifting focuses. }\end{array}$ \\
\hline 2 & $\begin{array}{l}\text { Create opportunities for open dialog within the community and with outside perspectives. Members } \\
\text { and their knowledge are valuable, but there is benefit in looking externally for inspiration too. }\end{array}$ \\
\hline 3 & Welcome and allow different levels of participation \\
\hline 3.1 & Core group - intensely committed to the group, typically the leaders of the CoP. \\
\hline 3.2 & Active group - regular attendees but do not have the same level of commitment or capability as the leaders. \\
\hline 3.3 & Peripheral group - passive participants (the majority of the community) who learn from their involvement. \\
\hline 4 & $\begin{array}{l}\text { Develop both public and private community spaces. Typically, CoP will operate in public places, but they } \\
\text { also need to be able to have private exchanges. Relationships generated within CoP will be individualised } \\
\text { and support specific non-group needs. }\end{array}$ \\
\hline 5 & $\begin{array}{l}\text { Focus on the value of the community. Feedback on the value and productivity of the CoP should be } \\
\text { interwoven into its management. }\end{array}$ \\
\hline 6 & $\begin{array}{l}\text { Combine familiarity and excitement. Providing familiarity supports the expectations of members within a } \\
\text { CoP. There should also be scope to explore and brainstorm both conventional and radical wisdom. }\end{array}$ \\
\hline 7 & $\begin{array}{l}\text { Find and nurture a regular rhythm for the community. The events and activities of the CoP should allow } \\
\text { the members to regularly meet, reflect, and evolve. The rhythm, or pace, should maintain an anticipated } \\
\text { level of engagement to sustain the vibrancy of the community, yet not be so fast-paced that it becomes } \\
\text { unwieldy and overwhelming in its intensity. }\end{array}$ \\
\hline
\end{tabular}


By understanding these actions and building local library programs to work with them, local governments can employ a library to help build a community of practice around: digital media, content creation, local economic development and other potential advantages of the Internet. A program needs to allow for the development of a natural evolution of community engagement, encouraging but allowing for an organic creation and re-creation over time. Local government within the context of libraries can build dialogue across the community as part of the process, which encourages participation at the three levels outlined above - core, active and peripheral.

The relationship between public and private involvement can be strengthened through the library context. The library can act as a mediator between public and private community stakeholders (Gilchrist 2004). These interactions serve to enhance the sense of community both in the digital and physical realms. The importance of both a familiar and yet dynamic and exciting hub, helps develop a regular rhythm for the local digital community hub or community of digital practice. Blewitt and Gambles (2010) outlined the process and implementation of the Library of Birmingham's project to provide a place for lifelong learning for the digital age. The new Library of Birmingham (LoB) building (at a budgeted cost of $£ 193$ million, US\$328 million) seeks to reinvent the library through new technologies and its dedication to learning, culture, arts and commerce. The lifelong learning project is ongoing and seeks to fashion a new paradigm, interweaving physical and virtual places to create areas of high productivity and creativity. The project positions the library within its physical setting of the city, capitalising on the affordances of old and new media to develop a multi-modal and multi-spatial interface that emphasises service provision to its community. As new technologies rewrite the way we participate, learn, and engage, the planning for the new LoB presents an exciting transition for libraries that focuses on knowledge management and creation, sustainability, heritage, and cultural diversity, as well as lifelong learning (Blewitt 2012; Blewitt and Gambles 2010).

\section{Libraries in the context of urban systems}

Of course, public libraries do not exist in isolation. They operate within the context of local communities, cities, and wider urban systems. In addition to the emergence of digital technologies, there is increasing acknowledgment that libraries play a specific role within cities and the community as public, third places. Just as the LoB has contextualised the development of a library to meet the needs of the City of Birmingham, each community and each local government needs to find its own way to create the desired lifestyle opportunities through the collective sum of its individual actions and identity. Local libraries are a central meeting point for local government and their community networks. They can provide the connections to interpret, define and grow the effective use of new digital technology within communities for more than just social and leisure purposes, and towards entrepreneurial initiatives and regional prosperity (Gilchrist 2004). 
Each community will need to interpret a community space, called a communication node, to reflect the authenticity and character of its physical and socio-economic environment (Zukin 2009). In response, local governments increasingly need to consider the concept and adoption of a glocalisation paradigm (Robertson 1995; Wellman 2002). Glocalisation is a portmanteau describing the simultaneous action towards both globalisation and localisation. Arising from the advent of a global network connectivity and its impact on economics and social interactions, it reflects the way in which local activities are generated, managed or represented in global contexts (Wellman and Hampton 1999). Blewitt (2012) suggests that libraries offer significant potential to generate and offer physical and digital spaces that allow community groups to 'explore, mediate and seek creative solutions' to local issues. In this way libraries encourage creative thinking and learning - acting as a 'people's university,' continuing an existing library role in a modern context. This requires a shift in the mentality of local government to encourage and support their librarians to redefine their role from knowledge guardians to knowledge brokers, solution-based thinkers, mentors, and coaches. The public library's role will necessarily be an evolving one, moving from event spaces to seminar and educational uses, from health fairs to exhibitions and workspaces. Blewitt (2012) draws on Oldenburg's (1989) notion of third place. Although the Internet allows people to access information anywhere, anytime, people are looking for something more than they can achieve at home or work: they are looking for the experience that is the 'drama community' (Frischer 2005). As is illustrated in the LoB project, many people are seeking to create a heterogeneous social space that allows for cultural freedom and the emergence of 'new political, commercial, educative, intellectual and experimental possibilities' (Blewitt 2012).

When we re-imagine the position of libraries within our communities and urban frameworks, we need to appreciate this glocalisation effect and develop ways to support local networks within a larger global structure. City strategies are starting to incorporate global positioning and competitiveness; however, at the same time, they need to acknowledge their local context with its specific identity and needs. Inherently social creatures, we learn, innovate, and develop more when we have a social community context in which to operate (Tuomi 2002). This research aims to establish how local government can re-think the role of libraries in fostering these connections and create cultures of innovations. This paper argues that libraries can contribute a novel and logical solution to this quest.

To date, little research has been undertaken into these challenges and opportunities from a library and city-strategy perspective. This paper seeks to further explore how library managers and local government policy initiators envisage and regulate the use of and development of digital technology for libraries. This study directly addresses this knowledge gap. It asks how key management and advisors of libraries perceive the changing role of these institutions. It also investigates ways to optimise the position of libraries as spaces that enable communities to participate in problem solving, engage in local issues, and increase community efficacy (Carroll and Reese 2003). In this way, this study seeks to conceptualise the library within the structure of a forward-thinking and digitally connected city and region. 


\section{Methodology}

Empirical data, in the form of qualitative expert interviews, was gathered to address the research questions. There were four linked questions:

- What are the challenges and opportunities of presenting the library as a communication node within the structure of local government?

- How do library managers and local government policy initiators envisage and regulate libraries as communication hubs?

- How do decision makers and stakeholders - inside and outside of libraries perceive the changing role of libraries?

- How can libraries optimise their position as spaces that enable communities to participate and that act as innovation hubs and communication nodes within the greater context of communities and local government areas?

The use of library management experts allowed for the collection of information that reflected a depth of experience and knowledge (Brogner, Littig and Wolfgang 2009) in relation to the strategic management, community role and existing uses of libraries. The 14 interviewees included library managers, state government library advisors and consultants, a Local Government Association policy advisor, a private library consultant, and Information Technology specialist librarians. Interviews were held in both New South Wales and Queensland, Australia. To retain anonymity in this research, the interviewees are referred to as 'library management' and are individually coded as ' $\mathrm{mpl}$ ' to 'mp14' (management participant). The participants were chosen for their depth of knowledge and experience within the library sector, knowledge and role in dealing with governance bodies (particularly local government), as well as their role in directing the future policy of libraries. Contact was initially made by email and phone calls as necessary. Each interview lasted approximately an hour. Appropriate ethical clearance was obtained through the University Human Research Ethics Committee of Queensland University of Technology. Prior to the interview, each participant was sent information including the questions, an information sheet, and a consent form.

The interviews were semi-structured, thus allowing for inquiry into emergent issues. The questions focused on these key topics:

- The changing roles of libraries in the digital age

(for community, economic development and lifelong education);

- The role and adoption of digital technology in libraries;

- The implications of the NBN rollout for libraries;

- The development of a sense of community in libraries, and;

- The physical changes to library buildings that relate to changes brought about by digital media.

Responses were coded and analysed in terms of the themes that emerged from within the data (Guest, MacQueen and Namey 2012). The three key themes were: the localisation of knowledge in a digitally global network; optimising and developing skills and talent; and technology resources and access. Each theme is discussed in turn below. 


\section{Findings}

It is a time to be bold and not think that our strengths of the past, which are very much around book lending (as a great strength), are necessarily going to be the future of the library. (mp7)

The library decision makers were generally positive about the future of public libraries and their ability to shift to the delivery of digital content and services. The interviewed library managers all saw the need for the library to shift its image into the digital age. E-books, Google, and library budget rationalisation all threaten to change the future direction of libraries. Although there was a comment that there was a daily need to defend the future of the library to others, including politicians and the public, there was also the response, that to question the future validity of the library in a Google world has 'missed the process of evolution of libraries' (mp2). Libraries offer something quite different and so much more in terms of meaning and process.

Libraries and books are strong. Really what sits behind that is the link between libraries and the content that is in books, which is the ideas, the thoughts, the information, the learning, the pleasure that we have historically, or traditionally, had from books, that books have reliably given us. I think it is very much the identity of the libraries, and even in the future to some extent. It is important as we transition more to this modern concept of the library and what it has always been about: learning, information, culture, and interaction. At no time in that would I say it is about a particular media. It is about how we handle this transition so we take the whole community with us. (mp7)

The key aspects of these transitions were investigated in the interviews. Three themes emerged in the analysis of the data, including the localisation of knowledge, talent and skill development, and technology resources. Each theme presented specific opportunities and barriers for the future positioning of libraries in terms of the digital technology and physical places, as perceived by the interviewees.

\section{Localisation of knowledge in a digitally global network}

To some extent, the content that is in the book stock will be replaced by the content that is in people and content that is online. It is about how we fuse all that together. (mp7)

Each library service is contextualised within a specific community. The library manager saw that understanding and meeting the needs of the community was a responsibility and a great strength of libraries. Communities can be dynamic and evolve, and the need to keep up to date with requirements and preferences of various socio-economic and interest groups underpinned collection strategies and service provision in libraries.

We are very interested in the multicultural community, to understand what languages they speak and also what languages they read. We buy collections in other languages when the population gets to about 2,500 ... We need to talk with them about what types of material they want us to supply. Is it books, magazines, or e-Books? (mp7) 


\section{It is important to have staff out in those communities and they need to have a sense of service and relationship with that community. (mp7)}

Critically, libraries are positioning themselves by building communities that are based on the interests of their population and in their specific location. These broader community-building activities would connect with the services that libraries already provide for their local population. Although there are vast quantities of 'how-to' information on the Internet, these libraries still found that there was strong support for local events that encouraged learning, collecting, and sharing, including and beyond providing information about how to use technology. As one library manager commented:

We have another program about raising chickens in your backyard (incredibly fraught with difficulties if it gets out of hand). The woman that we work with, actually brings in some chickens. The customers tell us what makes the program so valuable is that you actually get to see the chickens as part of the learning. And they are meeting other people in their neighbourhood who keep chickens and they find they have a lot in common. So they have access to the expert, and they have access to the chicken, and it is extraordinary outcome. It is just so rich with information. It ticks all the boxes in how we learn, how we interact, how we get expert information, and it is how we learn now ... I call it social learning. ( $\mathrm{mp} 7$ )

Interviewees also spoke of opportunities to create specific local content for the local community. This content would be designed to share the story of the local area through the eyes of the locals, the interviewee felt that this content creation could help build dynamic and evolving collections specific to their community. Such projects have already occurred, and these projects were highly localised, and set within digital technologies, taking advantage of the Internet and its global connectivity for local purposes. Through these types of project, libraries have become active creation spaces for locals and about local topics. What some libraries found was that 'distant others' who had an affinity with the area, or who just wanted to know more about the area, were connecting in using Internet technology. In this way, the local content could be shared globally.

It's a global society, so people move around a lot. There are a lot of people who have been a part of the community who don't live here anymore so it [these community digital projects] give them a chance to link back to the area. (mp9)

Public libraries, because they serve a local community, which is where the library is, what we have over something like Google is a local presence. It is actually about being able to tie that local physical presence to a local digital presence. So having a worldclass author presenting in the library, being able to speak to people, and being able to podcast that and then having it available digitally. It is one thing to see a world-class author online, and it is another to have a world-class author at your local library online. It is a much better feeling. Being able to have facilities that allow you to have a great experience with a great world-class speaker, and in this case an author. (mp7) 
Another aspect of localisation discussed was the provision of a local place to connect. This was particularly relevant for some small community libraries that combined physical elements (such as a deck overlooking a park that was accessible beyond library hours) to generate a 'dynamic community place,' 'ownership,' and 'fusion of outdoor and indoor activity' (mp7).

Within communities, the role of the library as a public realm that provides open access for anyone was noted. However, there were two sides to this discussion. The proponents of free access argued that it was critical that 'everybody feels free to come into libraries - like everyone belongs, nobody is surprised to see you here' (mp6). This approach was contrasted with certain instances in which security was required within libraries to manage the behaviour of patrons and ensure the safety and comfort of others: 'We have to manage the library so they are safe for all people, so sometimes that means removing people. That safety is not just the physical safety, but also the online safety of the community - this presents all types of challenges' (mp6).

Common to all interviews was the discussion of the library as a true public service, reaching out, and helping and engaging its local community. Libraries offered positive points of connection between community members and between community members and the local government: 'The combination of physical and local - that is our great strength. We are co-located with the community' (mp7).

The library decision makers discussed several areas of greatest risk to the future of libraries. One of these areas of risk was the potential inability of political decision makers and non-users of libraries to shift their perceptions of the library away from books towards learning, lifestyle, and community. The library decision makers who were interviewed viewed the service to the local community as being far more about lifestyle support in learning, information, and entertainment, than a single media and activity (that is, books and reading). The knowledge and role of elected officials becomes particularly pertinent in terms of managing this risk and understanding the potential of digital connectivity for their communities. This needs to operate as a partnership between the politicians and management for achieving the best results. 


\section{Optimising and developing skills or talents: staff and community}

A lot of things are about vision and leadership ... in a lot of the work I do these days the things that are missing are vision or leadership and then staff development. (mp14)

The interviewees acknowledged that the expertise or skills needed within the library were changing. The new role of the library in the digital age is to extend the skill set of library directors (leaders), staff, and the community. The new generation of library will need expertise that includes 'exceptional customer service, education, events programmers, marketing, and technology capabilities' (mp6).

Library staff are already required to be flexible and customer-oriented to meet a wide range of community needs. A specific ability to pick up the latest technology and help people to access library content was also noted by the interviewees.

We really need people who are fleet-footed, who can respond quickly to the needs of the customer, who can have any device put before them, one they have never seen before, and feel comfortable enough to sit down with the customer and work it out. (mp7)

The interviewees acknowledged that libraries do not need to own all the skills: there was a role for consultants and collaborators who could meet the skill needs for specific projects, particularly if these were technology-related. In other instances, consortia between libraries may supply a skill needed; as one manager commented: 'I encourage our staff to do collaborative projects with other libraries. We are all thinking about the same things so it makes sense' (mp2). Libraries may also provide the space or place for community members to bring in their own skills. Volunteers or other service providers can be connected with the established context of the library as a place: 'For instance, we provide the space for Justices of the Peace to come in and provide their volunteer services to the community' (mp7).

Some of the digital-project based events held across Australia, such as 'Libraryhack' (Libraryhack 2012), have brought people together from a range of backgrounds with various levels of technology literacy and skills. If they are carefully planned, these events can generate real outcomes with the combination of existing databases of government information being used in new ways. This type of event has positive outcomes creating user-led applications of digital technology, and at the same time building community, increasing the exposure of technology capabilities, and developing the creative presentation of local information. 
The manager described several instances in which libraries helped to support and even incubate local community service groups, such as Indigenous groups, youth support networks, and disability services. Libraries provided meeting spaces (formal and informal), along with services to encourage these local groups, and these activities were popular and highly successful. If stimulated and encouraged by decision makers within local government, there is no reason why the same level and quality of support could not also be provided for new entrepreneurial initiatives such as emerging creative industries start-ups. Early examples were mentioned that saw libraries supporting and encouraging small or solo businesses to develop, sometimes by providing a workspace or meeting space, or access to information or training. One of the interviewees observed that 'libraries are moving away from a co-location model to more integration of services and support' (mp11), which is particularly pertinent in the provision of support services across a variety of community needs.

With the rollout of the NBN, libraries have been identified as potential hubs of connectivity and education, providing training and skills for the use of technology. It has been a great opportunity for libraries, but, as one interviewee said: 'this is nothing new, libraries have been training people to use the Internet and other digital technologies since 1996' (mp6). The NBN was not seen as the only determining factor in the development of the library as a digitally connected hub, with or without NBN the libraries were experiencing the digital shift.

One of the considerations that factored into establishing training hubs was the need to avoid an institutional approach to the design of both of the physical spaces and learning material. This is important so that clients who have not been successful at school do not feel intimidated or excluded. There was a strong sense from the interviewees that community members falling into this category, with lower levels of literacy both for reading and computing, were most likely to have the greatest need for the training established in library digital hubs and that the library environment needed to welcome them. 


\section{Technology access and resources}

Technology progresses, constantly changing, revised and reinvented. One interviewee noted that dealing with continuous technological change is one of the challenges that libraries have to meet. This includes the notion of 'perpetual beta', that is, the first release of software beyond the developer will generally still have glitches and problems in functionality:

I think of the skills for library staff of the future is really getting their head around the concept of beta. Nothing is perfect anymore, everything to do with technology is about $80 \%$ to $90 \%$ there, but it is never perfect. By the time a technology is perfect we have moved on, it is gone, and it is about getting used to that concept. (mp 7)

Interviewees also identified an opportunity for libraries to work within global networks and share national and international resources. By collaborating with other libraries and organising into consortia, library management can maximise buying power and programming power to meet both library and local government needs. These efficiencies could produce not only desired product development (such as integrated cataloguing and referencing programs), but also considerable cost savings. Tied to any development of technology is the cost of 'keeping up.' This involves resourcing both the purchase of equipment and the training and maintenance that goes with it.

The issues of 'governance and perceived risk have had a limiting effect on libraries' (mp9), especially for the use of certain social media technologies. Many interviewees said this was the first year they have been allowed to use Facebook for the library. Others mentioned that they had not been able to access WiFi or certain applications because of IT policy restrictions imposed by their local government. A mentality fixed on finding solutions rather than problems was the recommendation of the library management. They were often frustrated by the limits of perceived issues and the blanket application of policy, which had not accounted for service provision, need, and innovative solutions. According to the interviewees, these types of constraints and unnecessary difficulties inhibited innovation and the adoption of technology for and within the library for the communities served by their local government. Similarly, when operating in a 'Google world' (mp14), it was also mentioned that the integration and seamless access to the library's resources was important, especially in the digital or virtual realm. One interviewee referred to 'the silo-ification of information' (mp9). This means that the library resources were provided by separate vendors in different systems and licence arrangements and 'they don't necessarily all work together' (mp9). 
Finally, several participants mentioned that libraries need to provide flexibility of space to accommodate the changing technology needs and systems: 'As books make way for technology and community connection spaces' (mp6), libraries of the future will indeed look different and will allow users to access information from different mediums. Library managers saw that the future physical design of libraries was conceptually tied to the integration of community and technology. These future physical spaces will also need to relate to the digital spaces of the library in terms of access points, conversations, events, and glocalisation (a way of representing and presenting the local community within the global context). Each of the library managers talked about the importance of 24-hour access to the library through the provision of the Internet. It was not seen as an additional service, but a required link.

\section{Discussion}

In the digital age, spaces for physical connection continue to matter. In fact, the move to more social and collaborative styles of learning and innovating has put an emphasis on 'getting people together' to share experiences of place and activities that foster engagement in learning. In a globalised economy, which allows for collaboration with anyone, anywhere in the world, the quality of place and experience becomes a critical point of difference for people and companies in their choice of location. This research has demonstrated how, within the urban structure, libraries often provide this critical public third place (Aabø and Audunson 2012; Oldenburg 1989), operating as an intensive node of connectivity and hub of activity. Carefully positioned within a city's structure plan, libraries can play a major role in the glocalisation of community (Wellman, 2002), business, services, and knowledge. Libraries, to varying degrees, help to position the city in a broader global context and to inspire citizens and communities to connect and engage in digital economies. This creates an opportunity for local government to direct and create a global positioning for their communities within the digital realm. It also physically or tangibly locates the hub within a trusted knowledge centre - the local public library. Emphasis on funding and local priorities, need to acknowledge and build this potential positioning to the advantage of local government for economic development, education and service provision.

The first key finding of the research is that libraries have a dynamic future when they position themselves as the link between people and ideas, thoughts, information, and the development of knowledge, specifically as information changes format and presentation in the digital realm. The evolving role of libraries will be to provide a bridge and ease the transition for the community, helping to make sense of the digital age and the opportunities that technology presents. 
The potential gains of the NBN infrastructure require people to use technology in productive ways. However, technology infrastructure means little if it is not adopted effectively (Tuomi 2002). Creating active examples and hands-on applications open up meaning and confidence for communities. The library examples of using and engaging communities demonstrate the benefits of social learning as a means of increasing the use of, and connection to, technology. Through socially conspired inspiration, innovation has a place to germinate and develop (Wenger, McDermott and Snyder 2002). A culture of creation evolves. This level of social and digital connection operates well at the local level. The library managers' examples of the popularity of social-based learning projects illustrate a potential for lifelong learning in the 'public university' (Blewitt 2012) that is the library. These community developments can be used to support local economic development through access to knowledge for businesses at all levels. They can also aid the development of local identity within global networks supporting tourism and the attraction of new businesses to an area. They can support startup businesses and sharing of knowledge about marketing, markets and Internet business practices. The extension of the digital global economy more widely through local communities opens opportunities for new businesses and economic activities to arise.

The second key finding is that library management envisage ways to capitalise on their strong community connection and understanding to create local communities of practice (Wenger 2002) as they come to centre more on the use of technology. To do this effectively, library management can utilise Wenger's seven actions for cultivating communities of practice within the strategic direction of their libraries. This is critical to establishing a nurturing environment for active community learning, and includes knowing their communities and their values, providing a context for open dialogue, and allowing for varying levels of participation. The examples given by the library managers also illustrate that combining the 'familiar' with elements of excitement can create dynamic places. Wenger (2002) suggests that this combination should allow scope for the exploration and brainstorming of conventional as well as radical wisdom. The library examples of bringing in external inspirations were valuable for gaining knowledge, sharing, and innovating, particularly programmed events, such as LibraryHack, and lifestyle events such as author talks, or learning about urban agriculture, e.g. raising backyard chickens or gardening.

A third key finding identified within this research relates to how libraries extend the lifestyle and business opportunities to their local area. There is a shifting focus of the library in the age of the Internet, from containment of information in the form of physical collections, to looking outwardly at its local community and actively considering which services and programs are suitable for clients' needs. Libraries are well positioned to understand their communities from a historical perspective, with their local history collections, as well as understanding the present needs of dynamic or shifting demographics. 
Linking these elements has vast potential for the development of dynamic places that are not just reminiscing in the past, but future and forward oriented both physically and virtually. When considering the positioning of cities in a global context, there can be little doubt that libraries currently play a key role and have the potential to expand this role in tandem with the goals of local governments. This research identified how local activities focused in the library sector could connect globally through Internet technology - glocalisation (Wellmann 2002). The discussion of ways this was actively happening across the library sector, suggest it can be a key strength for the physical presence of the library. The examples went beyond leisure activities, touching on areas of entrepreneurialism, business development, art, culture, health, and education. In regional communities this role is particularly pertinent. Libraries, in some instances, joined with other service providers to deliver increased access. For example, councils and community services may use the library to support their provision of face-to-face customer support. More than co-location, this was about an integration of information and service. Using libraries as knowledge places, in addition to hubs for communication and social interaction, maximises the benefit of technology across a community and saves a significant amount of money (Aabø 2009; Aabø and Audunson 2012). Library experts all drew on their usual practice of profiling the specific communities they serve to ensure that they develop a good understanding and strong relationship with those communities. This process allows a strong trust to build between communities and libraries. This trust opens communication and encourages involvement; trust encourages people to ask their unanswered questions, to pursue education, to reach for personal aspirations like the development of a business enterprise.

Now that technology has been freed from the tethers of the desktop and 'gone mobile,' the need to provide physical places that cater for a seamless transition from leisure and entertainment to civic engagement and entrepreneurialism will have an impact on the design and function of library spaces. To meet this need, libraries are creating more flexible and informal spaces, which allow for social connection in both serendipitous and programmed events. In the socialisation of the library as a place (Aabø and Audunson 2012), there is a further opportunity to build an interconnected hybrid of physical and virtual place, connecting people within and beyond the physical place of the library and its opening hours. The interviewees spoke of the need for $24 / 7$ access and this fusion of the place that is the library and its digital space is an important direction for further investigation and research for libraries within local government policy making.

In governing the access to online content, library managers were aware of concerns to minimise risk, and manage the security of that access. However, they were careful not to limit their vision of possibilities with fear of the unknown. Guidelines for management (including risk management) and an action-oriented approach to digital technologies and learning could assist in building the policy framework for implementing libraries as hubs for community networking. 


\section{Conclusions}

In returning to the research questions, a number of conclusions can be drawn. Four key challenges have been identified for further establishing libraries as communication hubs in local government areas: the public perception of the library (particularly limited views of the library simply being about books); the management of security risk (both perceived and real); constraints of digital technology (particularly the unmet vision of a truly global networked; and the cost of maintaining technology to keep up with the changing and evolving trends).

If libraries were to be further established as communication hubs, a broad range of opportunities would be presented, including:

- Brokering partnerships and links with other libraries, government agencies, and key players to create strong localised networks;

- Enhancing community lifestyles through activity, connection, and education;

- Minimising the digital divide within communities and increasing access and equity;

- Enhancing connectivity and lifelong learning across communities;

- Positioning local communities within the global network and its economies, and;

- Supporting local government community engagement as well as local economic development.

More innovative libraries are already establishing policy connections within the larger strategic directions of the communities they serve. Further engagement with economic development activities and programs at both local and state government levels could potentially encourage small business enterprises, creative industries, and community organisations. Rather than only being considered as part of the community development portfolio of local government operations, this study finds evidence to suggest that libraries have also a key role to play within the economic development portfolio of local government. Politicians that recognise this opportunity will formulate new policies that allow libraries to work across these old departmental boundaries.

The library has the potential to become a valuable tool for assessing and sharing community aspirations and directions by acting as a physical manifestation of the community it serves. In design and physical development, this means less paper within the library and more digital technology; it means spaces for collaboration and co-working, for quiet personal work, and for the use of high quality digital tools. Within the community, the library requires high visibility, connection to community spaces, and accessibility. 
Libraries have a long history of bringing people together in physical places to encourage the sharing of information, knowledge, and experience. However, the future of the modern library is the successful integration of these existing assets with the digital world and infrastructure such as the NBN that supports it. Next-generation libraries will be essential for supporting and connecting the strong, networked community that could be realised through the NBN. It is also noted that digital technology will evolve with or without NBN and library resources will continue to move to more digitally based content. Local government can utilise the resource and infrastructure of the knowledge centres of libraries to build strong communities to leverage economic development through the digital connection of the Internet. Local government can position their overall digital strategies with a strategic focus on the library as the central point or physical link with the communities and the global economy. The acceptance and support of both the politicians and the supporting levels libraries bureaucracy is vital to developing the levels of commitment and success of libraries as the digital hubs of communities. 


\section{References}

Aabø, S. 2009, 'Libraries and return on investment (ROI): a meta-analysis', New Library World, vol. 110, no. 7/8, pp. 311-24.

Aabø, S. \& Audunson, R. 2012, 'Use of library space and the library as place', Library; Information Science Research, vol. 34, no. 2, pp. 138-49.

Access Economics 2009, Impacts of a national high-speed broadband network, report prepared for Telstra Corporation Limited.

AGIMO, A.G.I.M.O. 2008, Consulting with Government - Online, canberra.

ALIA 2012, ALIA Internet access in public libraries survey 2011.

Bilandzic, M., \& Foth, M. 2013, 'Libraries as Coworking Spaces: Understanding User Motivations and Perceived Barriers to Social Learning', Library Hi Tech Journal, vol. 31, no. 2, pp. 254-73.

Blewitt, J. 2012, 'Reimagining the moral economy of the 'people's university", Power and Education, vol. 4, no. 1 , pp. 107-17.

Blewitt, J. \& Gambles, B. 2010, 'The Library of Birmingham project: Lifelong learning for the digital age ', Journal of Adult and Continuing Education, vol. 16, no. 2, pp. 52-66.

Brogner, A., Littig, B. \& Wolfgang, M. (eds) 2009, Interviewing experts, e-book, Macmillan Hampshire.

Buschman, J. \& Leckie, G.J. (eds) 2007, The library as place: history, community, and culture, Libraries Unlimited.

Carroll, J.M., \& \& Reese, D.D. 2003, 'Community Collective Efficacy: Structure and Consequences of Perceived Capacities in the Blacksburg Electronic Village.', paper presented to the Paper presented at the 36th Hawaii International Conference on System Sciences (HICSS), Big Island, Hawaii., Jan 6-9 2003.

Chowdhury, G., Poulter, A. \& McMenemy, D. 2006, 'Public Library 2.0: Towards a new mission for public libraries as a "network of community knowledge", Online Information Review, vol. 30, no. 4, pp. 45460 .

Cradduck, L.M. 2011, 'The future of the Internet Economy: Addressing challenges facing the implementation of the Australian National Broadband Network'.

Cubitt, S. 2006, 'Library', Theory, Culture \& Society, vol. 23, no. 2-3, pp. 581-90.

DBCDE 2009, Digital Economy Future Directions Final Report Australian Government, Canberra, p. 103, <www.dbcde.gov.au/digital_economy/final_report>.

DBCDE 2011a, National Digital Economy Strategy, vol. 2012, Australian Government, Canberra, <http://www.nbn.gov.au/>.

DBCDE 2011b, NBN - National Broadband Network - Australia, Australian Government Department of Broadband Communications and the Digital Economy, <http://www.nbn.gov.au/>.

Frischer, B. 2005, 'The Ultimate Internet Café: Reflections of a Practicing Digital Humanist about Designing a Future for the Research Library in the Digital Age', vol. pub 129. Library as Place: Rethinking Roles, Rethinking Space, no. February 2005.

Gilchrist, A. 2004, The Well-Connected Community: A Networking Approach to Community Development., The Policy Press, Bristol, UK.

Guest, G., MacQueen, K.M., \& \& Namey, E.E. 2012, Applied Thematic Analysis SAGE Publications, Inc

Gurstein, M. 2003, 'Effective use: A community informatics strategy beyond the digital divide', First Monday, vol. 8 , no. 12 .

Hardey, M. 2007, 'The city in the age of Web 2.0: A new synergistic relationship between place and people.', Information, Communication \& Society, vol. 10, no. 6, pp. 867-84.

Hayden, C. \& Ball-Rokeach, S. 2007, 'Maintaining the digital hub: locating the community technology center in a communication infrastructure', New Media \& Society, vol. 9, no. 2, pp. 235-57. 
Hayes, E. \& Morris, A. 2005, 'Leisure role of public libraries', Journal of Librarianship and Information Science, vol. 37, no. 3, pp. 131-9.

Hull, B. 2003, 'ICT and social exclusion: the role of libraries', Telematics and informatics vol. 20, no. 2, pp. 131-42.

Jahoda, G. 2012, 'Critical reflections on some recent definitions of "culture"', Culture \& Psychology, vol. 18, no. 3, pp. 289-303.

Jehlik, T. 2004, 'Information literacy in the public library', Nebraska Library Association Quarterly, vol. 35, no. 4 , p. 7 .

Kolbitsch, J., \& Maurer, H. 2006, 'The Transformation of the Web: How Emerging Communities Shape the Information we Consume.', Journal of Universal Computer Science, vol. 12, no. 2, pp. 187-213.

Kroeber, A.L., Kluckhohn, C. \& Untereiner, W. 1952, Culture: A critical review of concepts and definitions Vintage Books New York.

Leadbeater, C. 2000, The Weightless Society: Living in the new economy bubble., Texere, New York, London.

Libraryhack 2012, Events - Libraryhack: State Library of Queensland, Brisbane, viewed 13/11/12 2012, <http://libraryhack.org/events/>.

McShane, I. 2011, 'Public libraries, digital literacy and participatory culture', Discourse: Studies in the Cultural Politics of Education, vol. 32, no. 3, pp. 383-97.

Newman, J. 2007, 'Re-mapping The Public', Cultural Studies, vol. 21, no. 6, pp. 887-909.

Notley, T. \& Foth, M. 2008, 'Extending Australia's digital divide policy: an examination of the value of social inclusion and social capital policy frameworks', Australian Social Policy, vol. 7.

OEDC 2012, Laying the Foundation for the Internet Economy: Access to the Internet via a High-Speed Infrastructure", vol. No.201.

Oldenburg, R. 1989, The Great Good Place: Cafes, Coffee Shops, Bookstores, Bars, Hairsalons and other hangouts at the heart of community, Marlowe and Company, New York.

Quinn, S. \& McCallum, I. 2011, Living learning libraries: Standards and guidelines for NSW public libraries 3rd edition Library Council of New South Wales, Sydney

Robertson, R. 1995, 'Glocalization: Time-Space and Homogeneity-Heterogeneity', in S.L.R.R. M. Featherstone (ed.), Global Modernities, Sage, London pp. 25-44.

Russell, S.E. \& Jie Huang 2009, 'Libraries' role in equalizing access to information', Library Management, vol. 30 , no. $1 / 2$, pp. $69-76$.

SLQ 2012, The Library Dividend Summary Report, State Library of Queensland, Queensland Government, Brisbane.

State Library of NSW 2011, Public Library Statistics 2010-2011, State Library NSW, Sydney.

Strover, S., Chapman, G. \& Waters, J. 2004, 'Beyond community networking and CTCs: access, development, and public policy', Telecommunications Policy, vol. 28, no. 7,Äi8, pp. 465-85.

Tuomi, I. 2002, Networks of Innovation, Oxford University Press, New York.

Wellman, B. 2002, 'Little Boxes, Glocalization, and Networked Individualism.', Digital Cities II: Second Kyoto Workshop on Digital Cities, ed. M. Tanabe P. van den Besselaar \& T. Ishida, vol. LNCS 2362, pp. 10-25, Springer, Heidelberg, Germany, pp. 10-25.

Wellman, B. \& Hampton, K. 1999, 'Living Networked in a Wired World', Contemporary Sociology, vol. 28, no. 6 .

Wenger, E., McDermott, R. \& Snyder, W.M. 2002, Cultivating Communities of Practice Harvard Business Press.

Zukin, S. 2009, Naked City: The Death and Life of Authentic Urban Places, Oxford University Press. 